\title{
In vitro anti-BK polyomavirus activity of imidazo[1,2-c]pyrimidine and pyrimido[1,6-a]pyrimidine derivatives
}

\author{
Roman Solomyannyi ${ }^{a}$, Oleg Mitiukhin ${ }^{a}$, Mark Prichard ${ }^{b}$, Scott James ${ }^{b}$, Carol Hartline ${ }^{b}$, Victor \\ Zhirnov $^{\mathrm{a}}$ and Volodymyr Brovarets ${ }^{\mathrm{a}^{*}}$
}

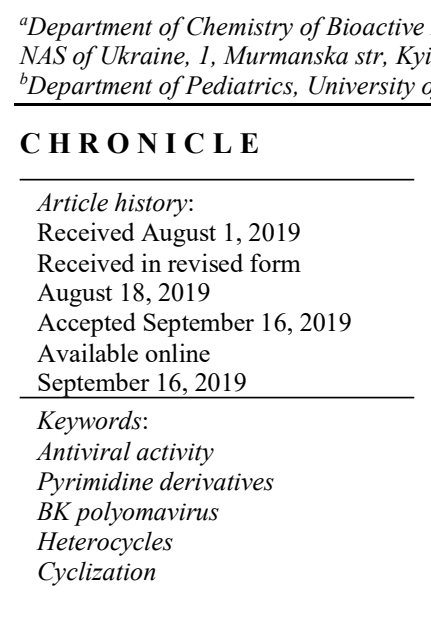

\section{Introduction}

Viruses are the leading cause of severe complications in immunocompromised patients. Human Polyomavirus 1 (HPyV-1), more commonly known as BK virus (BKV) or BK polyomavirus (BKPyV), is a common infection acquired in childhood which then becomes latent. Modern immunosuppressive therapy has dramatically improved graft survival in transplant patients. Transplant patients are prone to the reactivation of viruses which are usually latent in immunocompetent people, such as herpes viruses (CMV, EBV, HSV, VZV, and HHV-8) and polyomaviruses (BK and JC), whether those viruses are latent in the recipient or in the organ transplanted. ${ }^{1}$ In particular, with the implementation of more potent immunosuppressive drugs, BKV has become an emerging pathogen in kidney and bone marrow transplant recipients where it often causes associated nephropathy and haemorrhagic cystitis, respectively. Among the various pathogens, BKV can directly cause graft dysfunction. BKV is a frequently reactivating in transplant recipients after kidney and haematopoietic stem cell

* Corresponding author.

E-mail address: brovarets@bpci.kiev.ua (V. Brovarets)

(C) 2020 Growing Science Ltd. All rights reserved

doi: $10.5267 /$ j.ccl.2019.9.001 
transplantation. ${ }^{2,3}$ This reactivation can lead to BKV-associated nephropathy and compromised kidney function. ${ }^{4}$ Polyomavirus BK infection is asymptomatic but graft outcome is poor if the patient develops tissue-invasive nephropathy.

The basic treatment strategy is immunosuppressive drug tapering, which is currently the recommended treatment of BKV viremia after kidney transplantation, ${ }^{5}$ and using immunosuppressive drugs with antiviral properties are under evaluation. ${ }^{6}$ The inhibitors of the mammalian target rapamycin (mTOR) also have data supporting their potential use for BKV infections after transplantation. ${ }^{7,8}$ Despite almost 50 years of research on $\mathrm{BKPyV}$, there is still no effective antiviral therapy. There are few treatments and vaccines available for antiviral therapies thus far. However, vaccines are likely to suffer from waning $\mathrm{CD}^{+} \mathrm{T}$ cell counts and thus antiviral therapies are a promising therapeutic strategy. Limited therapies exist to treat these normally benign infections, and with increasing numbers of patients displaying symptoms of immunodeficiency, the need for novel strategies by which to treat opportunistic viral infections is high.

Anti-BKV agents reported in literature include fluoroquinolones (ciprofloxacin, levofloxacin), nucleotide analogues (cidofovir, brincidofovir), and artesunate. ${ }^{9,10}$ Fluoroquinolones, which inhibit Type II topoisomerases by stabilizing the linkage between the enzyme and DNA, have been shown to inhibit the BK virus replication. An effective and safe antiviral should have a selectivity index (SI) of $>10$, but these agents have an SI $<4$. Therefore, they may not be efficacious in eradication of the virus in vivo. ${ }^{11}$ Current findings from in vivo prospective studies do not support the use of quinolones to prevent posttransplant BK virus infection in kidney-transplant patients receiving heavy immunosuppression. ${ }^{12-14}$ Hence, fluoroquinolones are not recommended for prophylaxis or therapy. ${ }^{15}$ Although the efficacy of quinolones is less than adequate for an anti-polyomavirus agent, these data suggest that the BKV encoded helicase activity may represent a significant drug target for further development.

Nevertheless, the cytosine analog, cidofovir, and its prodrug, brincidofovir (CMX-001), showed a significant inhibition of BK virus DNA replication in vitro. This has been used by clinicians both intravenously and as bladder instillation. However, there is only weak evidence for the use of cidofovir as an in vivo anti-BKV drug. ${ }^{16}$ Also, the pronounced nephrotoxicity limits its use particularly in renal transplantation. ${ }^{10}$ In addition, cidofovir-resistance has been noted for multiple viruses. ${ }^{17}$ Cidofovirresistance represents a significant limitation for use of this compound to treat polyomavirus replication.

Leflunomide and its active metabolite teriflunomide also have antiviral effect against BKV, which is thought to be due to inhibiting viral replication by disruption of virion assembly at the nucleocapsid. ${ }^{18}$ This is accompanied by a significant host cytostatic effect with non-specific pyrimidine depletion. ${ }^{19}$ Leflunomide activity against $\mathrm{BKV}$ is modest and the $\mathrm{SI}$ is low. ${ }^{20}$ The in vivo data suggest that leflunomide may be a potentially effective medication for treating BKV without significant toxicity. ${ }^{21}$ On other hand, pharmacodynamic analysis revealed no association between leflunomide concentrations and BK viral PCR reductions. Multivariate analysis demonstrated that leflunomide therapy was not associated with BK viral clearance. ${ }^{22}$ In any event, randomized controlled studies are needed to determine the utility of leflunomide for BK viremia.

Currently, leflunomide, cidofovir, and quinolones are not Food and Drug Administration (FDA)approved for BKV treatment. Tacrolimus, cyclosporine $\mathrm{A}$ and sirolimus are approved for the prevention of organ rejection in the kidney transplant recipients, but not specifically to BKV prevention or treatment. Individuals with weakened immune responses face the prospect of acquiring severe diseases from benign viral infections. Treating these diseases can be challenging due to impaired immune function. Thus, it is imperative to find novel antiviral therapies that target host or viral proteins and are able to work independently of the immune system. Thus, there is an unmet need for novel antiviral drugs. 
The first therapeutic target is the viral receptor on host cells. Initial encounters between a virus and a host cell are mediated through viral surface components. The primary receptor binding determinant on the BKV capsid is the VP-1 protein. The virus attaches to the cell surface by recognition of oligosaccharides terminating in alpha(2,3)-linked sialic acid. ${ }^{23}$ Anti-BKV activity of nine sialic acid derivatives have been tested. ${ }^{24}$ Compound 2-(hydroxymethyl)-6-(nonyloxy)tetrahydro- $2 \mathrm{H}$-pyran3,4,5-triol, showed antiviral activity with a $\mathrm{EC}_{50}$ of $6.35 \pm 2.17 \mu \mathrm{M}$, and a neutral red SI of 30.51 \pm 2.02 . All other sialic acid derivatives tested were inactive.

Among compounds capable of disrupting viral transport a slight anti-BKV activity was found for chloroquine, nystatin, amphotericin $\mathrm{B}$, and colchicine. ${ }^{24} \mathrm{~A}$ recently identified inhibitor of viral transport, Retro-2cycl, and its derivatives have been evaluated to inhibit human BKV in tissue culture, ${ }^{25}$ and in the kidneys of mice ${ }^{26}$. Variety of compounds targeting different steps in the BKV life cycle have been tested in vitro, however, none of these agents has shown efficacy in vivo. ${ }^{26,27}$

Unfortunately, no specific antiviral agent against BKV has been approved yet and the only therapeutic option is a modulation of the immunosuppressive drug regimen to improve immune control, though doing this may increase the risk of allograft rejection. Hence, there is an urgent need for development of a safe and efficacious antiviral agent against BKV.

Substituted pyrimidine derivatives (non-nucleosides) are found to be associated with various biological activities, including activity against different DNA and RNA viruses. ${ }^{28}$ Previously, we showed that some pyrimidine derivatives have potent in vitro antiviral activity against polyovirus-3. ${ }^{29}$ The present study focuses on the anti-BKV activity of pyrimidine derivatives which were synthesized at V.P. Kukhar Institute of Bioorganic Chemistry and Petrochemistry (Ukraine).

\section{Results and Discussion}

\section{Chemistry}

Imidazo[1,2-c]pyrimidine derivatives 1-3 and pyrimido[1,6- $a$ ]pyrimidine derivatives 4,5 (Table 1) have been synthesized from 3-(R-amino)-2-(methyl(phenyl)sulfonyl)acrylonitriles by refluxing with 1chloro-2-isocyanatoethane or 1-chloro-3-isocyanatopropane and triethylamine ${ }^{30}$ (Scheme 1).

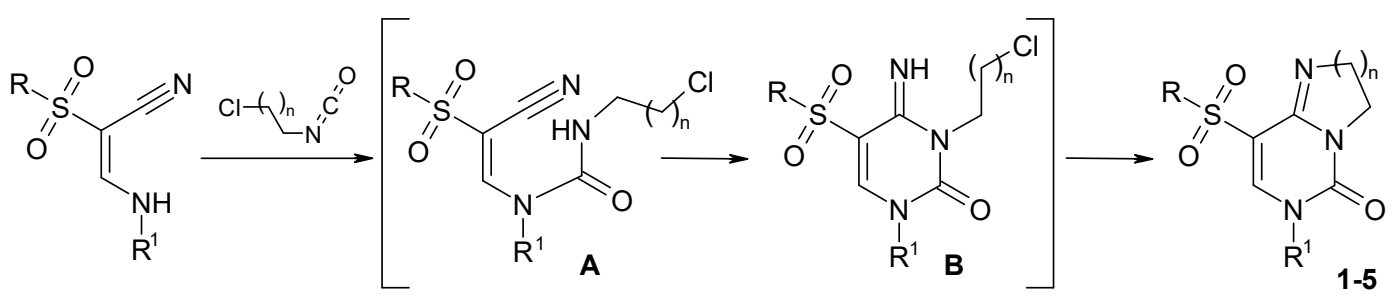

$$
\begin{gathered}
1 \mathrm{R}=\mathrm{Me}, \mathrm{R}^{1=}=\mathrm{H}, \mathrm{n}=1 ; 2 \mathrm{R}=\mathrm{Me}, \mathrm{R}^{1}=\mathrm{Bn}, \mathrm{n}=1 ; \mathbf{3} \mathrm{R}=\mathrm{Ph}, \mathrm{R}^{1}=4-\mathrm{MeC}_{6} \mathrm{H}_{4}, \mathrm{n}=1 ; \\
\mathbf{4} \mathrm{R}=\mathrm{Me}, \mathrm{R}^{1}=\mathrm{Bn}, \mathrm{n}=2 ; \mathbf{5} \mathrm{R}=\mathrm{Me}, \mathrm{R}^{1}=\mathrm{Pr}, \mathrm{n}=2
\end{gathered}
$$

Scheme 1. Synthesis of imidazo[1,2-c]pyrimidines 1-3 and pyrimido[1,6- $a$ ]pyrimidines 4,5. Reagents and conditions: 1-chloro-2-isocyanatoethane or 1-chloro-3-isocyanatopropane, TEA, dioxane, reflux, $3 \mathrm{~h}$.

First, the isocyanate group acylates the NH fragment of the initial acrylonitriles to form intermediate A, followed by nucleophilic attack of the nitrile group, which leads to intermediate $\mathbf{B}$. The intramolecular $\mathrm{N}$-alkylation of the resulting imino group gives products $\mathbf{1 - 5}$. 
Table 1. Chemical structures of synthesized compounds

\begin{tabular}{|c|c|c|}
\hline Compound & Structure & Name \\
\hline 1 & & $\begin{array}{l}\text { 8-(methylsulfonyl)-2,6- } \\
\text { dihydroimidazo[1,2-c]pyrimidin- } \\
5(3 H) \text {-one }\end{array}$ \\
\hline 2 & & $\begin{array}{l}\text { 6-benzyl-8-(methylsulfonyl)-2,6- } \\
\text { dihydroimidazo[1,2-c]pyrimidin- } \\
5(3 H) \text {-one }\end{array}$ \\
\hline 3 & & $\begin{array}{l}\text { 6-(4-methylphenyl)-8-(phenylsulfonyl)- } \\
\text { 2,6-dihydroimidazo[1,2-c]pyrimidin- } \\
\text { 5(3H)-one }\end{array}$ \\
\hline 4 & & $\begin{array}{l}\text { 7-benzyl-9-(methylsulfonyl)-2,3,4,7- } \\
\text { tetrahydro- } 6 H \text {-pyrimido[1,6- } \\
\text { a]pyrimidin-6-one }\end{array}$ \\
\hline 5 & & $\begin{array}{l}\text { 9-(methylsulfonyl)-7-propyl-2,3,4,7- } \\
\text { tetrahydro-6H-pyrimido[1,6- } \\
\text { a]pyrimidin-6-one }\end{array}$ \\
\hline
\end{tabular}

\section{Biology}

The obtained results of assays for BKV are summarized in Table 2. In general all the synthesized novel imidazo[1,2-c]pyrimidine and pyrimido[1,6- $a$ ]pyrimidine derivatives exerted antiviral activity in vitro against the $\mathrm{BK}$ polyomavirus strain. However, among the imidazo[1,2-c]pyrimidine and pyrimido[1,6- $a$ ]pyrimidine derivatives compound $\mathbf{2}$ and $\mathbf{5}$, respectively, were the most effective ones in primary assays (Table 2). The compounds 1, 3 and $\mathbf{4}$ showed insignificant activities against the BK polyomavirus with the range levels of $\mathrm{SI}_{50}$ from $>2$ to $>7$. The positive control compound cidofovir was active as expected in the assay. Although antiviral activity was evident in secondary assays, significant virus inhibition occurred at or near the cytotoxic concentration $\left(\mathrm{SI}_{90}=1\right)$.

The nature of the substituent on the pyrimidine ring is determinant for the extent of each synthesized compound's activity, which might have an influence on its inhibiting mechanism of action. Attaching the phenyl group to the N-6 position in the pyrimidine ring of 8-(methylsulfonyl)-2,6dihydroimidazo[1,2-c]pyrimidin-5(3H)-one (compound 1) considerably enhances the antiviral activity of the latter (compound 2), whereas a substitution of the methyl substituent by the phenyl one in the 
sulfonyl group results in an inverse effect (compound 3). On the contrary, the insertion of the phenyl substituent to the analogical position in the pyrimidine ring of the pyrimido[1,6- $a$ ]pyrimidine structure (compound 4) reduces the antiviral activity relative to the similar imidazo[1,2-c]pyrimidine derivative (compound 2). But on the other hand, the substitution of the phenyl group in this place by the alkyl group increases the antiviral activity (compound 5). These observations may promote further developments of our research in this field to obtain compounds with a better pharmacological profile than standard drugs and serve as templates for the construction of better drugs to combat the viral infection.

Table 2. Antiviral activity and cytotoxicity of the pyrimidine derivatives against BK polyomavirus (strain Gardner) in HFF cell line. Compound concentrations are in $\mu \mathrm{M}$.

\begin{tabular}{|c|c|c|c|c|c|}
\hline \multirow{2}{*}{ Compound } & \multicolumn{5}{|c|}{ strain Gardner } \\
\hline & $\mathrm{EC}_{50}$ & $\mathrm{EC}_{90}$ & $\mathrm{CC}_{50}$ & $\mathrm{SI}_{50}$ & SI90 \\
\hline & \multicolumn{5}{|c|}{ Primary assays* } \\
\hline 1 & 22.39 & 142.16 & $>150.0$ & $>7$ & $>1$ \\
\hline 2 & 0.66 & 1.03 & $>150.0$ & $>229$ & $>146$ \\
\hline 3 & 93.44 & 114.90 & $>150.0$ & $>2$ & $>1$ \\
\hline 4 & 21.62 & 28.33 & $>150.0$ & $>7$ & $>5$ \\
\hline 5 & 0.96 & 1.14 & $>150.0$ & $>157$ & $>132$ \\
\hline \multirow[t]{2}{*}{ Cidofovir } & 0.24 & 9.53 & $>150.0$ & $>600$ & $>16$ \\
\hline & \multicolumn{5}{|c|}{ Secondary assays ${ }^{\&}$} \\
\hline 2 & 31.1 & $>100.0$ & $>100.0$ & $>3$ & 1 \\
\hline 5 & 31.7 & $>100.0$ & $>100.0$ & $>3$ & 1 \\
\hline Cidofovir & 0.42 & 41.87 & $>100.0$ & $>238$ & $>2$ \\
\hline
\end{tabular}

The large T antigen (LTA) coding almost one half of the viral genetic information was evaluated as a potential target. It was reported that dihydropyrimidine derivatives inhibit BK polyomavirus replication and propagation by specifically inhibiting $\mathrm{T}$ antigen, and/or a cellular chaperone Hsp $70 .^{31}$ It is possible that a similar mechanism could also turn out to be one of the ones intrinsic to the tested compounds in this report.

The synthesis of new molecules that parallel certain critical structural properties of compounds with known bioactivity is an important aspect of antiviral drug development. Additional research needs to be done to better understand BKV biology, which could give direction to the ongoing antiviral screening of lead compounds and could also enable the identification of potential new targets to block BKV replication.

\section{Conclusions}

Pyrimidine is a core structure in a wide variety of compounds that have diverse biological and chemical applications. Pyrimidine derivatives are therefore a potentially useful starting point in the drug discovery process. In this study, five substituted pyrimidine derivatives were synthesized and their antiviral activity against BKV was tested. Primary screening showed that two of the compounds exhibited favorable SI, however secondary testing of these two compounds demonstrated insignificant antiviral activity against BKV. While this study was unable to confirm the antiviral activity of this series of compounds, it does provide useful information on specific analogs with antiviral activity in vitro that can be further modified to identify more active inhibitors.

\section{Acknowledgements}

We would like to thank Enamine Ltd for the material and technical support. These studies were funded in whole or in part with Federal funds from the National Institutes of Allergy and Infectious Diseases, National Institutes of Health, Department of Health and Human Services, under contract HHSN272201100016I (MNP). 


\section{Experimental}

General procedure for the synthesis of compounds 1-5

To a solution of appropriate 3-(R-amino)-2-(methyl(phenyl)sulfonyl)acrylonitriles $(2.15 \mathrm{mmol})$ in dioxane $(5 \mathrm{ml}), 0.27 \mathrm{~g}(2.26 \mathrm{mmol})$ of 1-chloro-2-isocyanatoethane or $0.31 \mathrm{~g}(2.26 \mathrm{mmol})$ of 1-chloro13 -isocyanatopropane and $0.4 \mathrm{ml}(2.29 \mathrm{mmol}) \mathrm{Et} 3 \mathrm{~N}$ are added successively. The reaction mixture is boiled under stirring for $2 \mathrm{~h}$, then cooled to room temperature and the precipitate is filtered off with Et $3 \mathrm{~N} \cdot \mathrm{HCl}$. The filtrate is evaporated under reduced pressure, the residue is recrystallized from ethanol. Physical and spectral properties of compounds 1-5 see in article. ${ }^{30}$

\section{Cells culture and virus strains}

The preparation of human foreskin fibroblast (HFF) cells was described by methods published previously and were derived from human foreskin tissue obtained from the University of Alabama at Birmingham tissue procurement facility with approval from the institutional review board. ${ }^{32}$ The Gardner strain of BKV was obtained from ATCC (Manassas VA). HFF cells were passaged in minimum essential media (MEM) with Earle's salts with the addition of $10 \%$ fetal bovine serum (FBS, Hyclone, Inc. Logan UT), and standard concentrations of L-glutamine, penicillin and gentamycin. All the HFF cells used in the study were utilized with fewer than 10 passages.

\section{Antiviral and Cytotoxicity Assays}

Cell viability was assessed with the CellTiter-Glo Luminescent Cell Viability Assay (Promega) using manufacturer's protocol. Standard methods were used to calculate the $50 \%$ cytotoxic level $\mathrm{CC}_{50} .{ }^{33}$

Primary assays for BKV were performed in 384-well plates containing monolayers of HFF cells. ${ }^{32}$ Compound dilutions ranging from $0.048-150 \mu \mathrm{M}$ were prepared in plates containing cells which were subsequently infected at an MOI of 0.001. After a $7 \mathrm{~d}$ incubation, total DNA was prepared and genome copy number was quantified by qPCR using the primers for the BKV VP1 gene, and the BKV probe. Plasmid pMP526 served as the DNA standard for quantification purposes. ${ }^{34}$ Compounds were confirmed in a similar assay in 96-well plates according to established laboratory protocols with the compounds added $1 \mathrm{~h}$ post-infection to identify compounds that inhibit early stages of replication including adsorption and entry. Genome copy number was determined by methods described above. For all assays, the concentration of compound that reduced virus titer by $50 \%\left(\mathrm{EC}_{50}\right)$ was interpolated from the experimental data. Cytotoxicity was evaluated in a parallel plate with equivalent compound exposure, an equivalent number of cells. Cidofovir was selected as reference compounds on the basis of its reported antiviral activity. It was purchased from the University of Alabama Hospital Pharmacy.

\section{References}

1 Aguilar C., Husain S., and Lortholary O. (2018) Recent advances in understanding and managing infectious diseases in solid organ transplant recipients. F1000Res, 7, f1000 Faculty Rev - 661.

2 Breuer S., Rauch M., Matthes-Martin S., Lion T. (2012) Molecular diagnosis and management of viral infections in hematopoietic stem cell transplant recipients. Mol. Diagn. Ther., 16, 63-77.

3 Cesaro S., Dalianis T., Hanssen Rinaldo C., Koskenvuo M., Pegoraro A., Einsele H., Cordonnier C. Hirsch H.H. (2018) ECIL-6 Group ECIL guidelines for the prevention, diagnosis and treatment of BK polyomavirus-associated haemorrhagic cystitis in haematopoietic stem cell transplant recipients. J. Antimicrob. Chemother. 73 (1) 12-21.

4 Elfadawy N., Flechner S.M., Schold J.D., Srinivas T.R., Poggio E., Fatica R., Avery R., Mossad S.B. (2014) Transient versus persistent BK viremia and long-term outcomes after kidney and kidney-pancreas transplantation. Clin. J. Am. Soc. Nephrol. 9 (3) 553-561. 
5 Westphal S.G., Lyden E.R., Langewisch E.D., Miles C.D. (2017) BK viremia surveillance and outcomes in simultaneous pancreas-kidney transplant recipients. Clin. Transplant. 31 (8) e13010.

6 Lamarche C., Orio J., Collette S., Senécal L., Hébert M.J., Renoult É., Tibbles L.A., Delisle J.S. (2016) Polyomavirus and the Transplanted Kidney. Immun. Therap. Appr. Transpl. 100 (11) 22762287.

7 Bowman L.J., Brueckner A.J., Doligalski C.T. (2018) The Role of mTOR Inhibitors in the Management of Viral Infections: A Review of Current Literature Transplantation. 102 (2S Suppl 1) 50-59.

8 Mallat S.G., Tanios B.Y., Itani H.S., Lotfi T., McMullan C., Gabardi S., Akl E.A., Azzi J.R. (2001) CMV and BKPyV Infections in Renal Transplant Recipients Receiving an mTOR Inhibitor-Based Regimen Versus a CNI-Based Regimen: A Systematic Review and Meta-Analysis of Randomized, Controlled Trials. Clin. J. Am. Soc. Nephrol. 712 (8) 1321-1336.

9 Chemaly R.F., Hill J.A., Voigt S., Peggs K.S. (2019) In vitro comparison of currently available and investigational antiviral agents against pathogenic human double-stranded DNA viruses: A systematic literature review. Antiviral Res. 163, 50-58.

10 Santeusanio A.D., Lukens B.E., Eun J. (2017) Antiviral treatment of BK virus viremia after kidney transplantation. Am. J. Health. Syst. Pharm. 74 (24) 2037-2045.

11 Khalil M.A.M., Khalil M.A.U., Tan J., Khan T.F.T. (2018) Fluoroquinolones and BK Virus Nephropathy: A Myth or a Reality. Indian J. Nephrol. 28 (4) 257-264.

12 Lebreton M., Esposito L., Mengelle C., Del Bello A., Delarche A., Dörr G., Milongo D., Marion O., Izopet J., Kamar N. (2016) A 3-month course of ciprofloxacin does not prevent BK virus replication in heavily immunosuppressed kidney-transplant patients. J. Clin. Virol. 79, 61-67.

13 Knoll G.A., Humar A., Fergusson D., Johnston O., House A.A., Kim S.J., Ramsay T., Chassé M., Pang X., Zaltzman J., Cockfield S., Cantarovich M., Karpinski M., Lebel L., Gill J.S. (2014) Levofloxacin for BK virus prophylaxis following kidney transplantation: A randomized clinical trial. JAMA 312, 2106-2114.

14 Lee B.T., Gabardi S., Grafals M., Hofmann R.M., Akalin E., Aljanabi A., Mandelbrot D.A., Adey D.B., Heher E., Fan P.-Y., Conte S., Dyer-Ward C., Chandraker (2014) A Efficacy of levofloxacin in the treatment of BK viremia: A multicenter, double-blinded, randomized, placebo-controlled trial. Clin. J. Am. Soc. Nephrol. 9, 583-589.

15 Hirsch H.H., Randhawa P.S. (2019) BK Polyomavirus in Solid Organ Transplantation - Guidelines from the American Society of Transplantation Infectious Diseases Community of Practice. Clin. Transplant: e13528. doi: 101111/ctr13528 [Epub ahead of print].

16 Schneidewind L., Neumann T., Schmidt C.A., Krüger W. (2018) Comparison of intravenous or intravesical cidofovir in the treatment of BK polyomavirus-associated hemorrhagic cystitis following adult allogeneic stem cell transplantation-A systematic review. Transpl. Infect. Dis. 20 (4) e12914.

17 Razonable R.R. (2018) Drug-resistant cytomegalovirus: clinical implications of specific mutations. Curr. Opin. Organ. Transplant. 23 (4) 388-394.

18 Teschner S., Burst V. (2010) Leflunomide: a drug with a potential beyond rheumatology. Immunotherapy 2 (5) 637-650.

19 Bernhoff E., Tylden G.D., Kjerpeseth L.J., Gutteberg T.J., Hirsch H.H., Rinaldo C.H. (2010) Leflunomide inhibition of BK virus replication in renal tubular epithelial cells. J. Virol. 84, 21502156.

20 Farasati N.A., Shapiro R., Vats A., Randhawa P. (2005) Effect of leflunomide and cidofovir on replication of BK virus in an in vitro culture system. Transpl. 79 (1) 116-118.

21 Chen X.-C., Liu T., Li J.-J., He C., Meng W.-T., Huang R. (2013) Efficacy and Safety of Leflunomide for the Treatment of BK Virus-Associated Hemorrhagic Cystitis in Allogeneic Hematopoietic Stem Cell Transplantation Recipients. Acta Haematol. 130, 52-56.

22 Krisl J.C., Taber D.J., Pilch N., Chavin K., Bratton C., Thomas B., McGillicuddy J., Baliga P. (2012) Leflunomide efficacy and pharmacodynamics for the treatment of BK viral infection. Clin. J. Am. Soc. Nephrol. 7 (6) 1003-1009. 
23 Low J.A., Magnuson B., Tsai B., and Imperiale M.J. (2006) Identification of gangliosides GD1b and GT1b as receptors for BK virus. J. Virol. 80, 1361-1366.

24 Randhawa P., Farasati N.A., Huang Y. (2007) BK Virus replication in vitro: limited effect of drugs interfering with viral uptake and intracellular transport. Antimicrob. Agents. Chemother. 51 (12) 4492-4494.

25 Nelson C.D., Carney D.W., Derdowski A., Lipovsky A., Gee G.V., O’Hara B., Williard P., DiMaio D., Sello J.K., Atwood W.J. (2013) A retrograde trafficking inhibitor of ricin and Shiga-like toxins inhibits infection of cells by human and monkey polyomaviruses. mBio 4, e00729-13.

26 Maru S., Jin G., Desai D., Amin S., Shwetank, Lauver M.D., Lukacher A.E. (2017) Inhibition of retrograde transport limits polyomavirus infection in vivo. $m$ Sphere 2, e00494-17

27 Carbone M., Rudzinski J., Bocchetta M. (2003) High throughput testing of the SV40 Large T antigen binding to cellular p53 identifies putative drugs for the treatment of SV40-related cancers. Virology 315 (2) 409-414.

28 Kumar S., Narasimhan B. (2018) Therapeutic potential of heterocyclic pyrimidine scaffolds. Chem. Cent. J. 12, 38.

29 Solomyannyi R., Slivchuk S., Smee D., Choi J., Rusanov E., Zhirnov V., Brovarets V. (2018) In vitro activity of the novel pyrimidines and their condensed derivatives against poliovirus. Current Bioactive Comp. 14 (4) 1-9.

30 Solomyannyi R.N., Shablykina O.V., Moskvina M.S., Khylia V.P., Rusanov E.B., Brovarets V.S. (2019) 8-(Methyl(phenyl)sulfonyl)-2,6-dihydroimidazo[1,2-c]-pyrimidin-5(3H)-ones and 9(methyl(phenyl)sulfonyl)-2,3,4,7-dihydro-6H-pyrimido[1,6- $a$ ]pyrimidin-6-ones: synthesis and antiviral activity. Chem. Heterocycl. Compd. 55 (4/5) 401-407.

31 Manos-Turvey A., Al-Ashtal H.A., Needham P.G., Hartline C.B., Prichard M.N., Wipf P., Brodsky J.L. (2016) Dihydropyrimidinones and -thiones with improved activity against human polyomavirus family members. Bioorg. Med. Chem. Lett. 26, 5087-5091.

32 Prichard M.N., Williams J.D., Komazin-Meredith G., Khan A.R., Price N.B., Jefferson G.M., Harden E.A., Hartline C.B., Peet N.P., Bowlin T.L. (2013) Synthesis and antiviral activities of methylenecyclopropane analogs with 6-alkoxy and 6-alkylthio substitutions that exhibit broadspectrum antiviral activity against human herpesviruses. Antimicrob. Agents Chemother. 57, 35183527.

33 Chou S., Merigan T.C. (1983) Rapid detection and quantitation of human cytomegalovirus in urine through DNA hybridization. N. Engl. J. Med. 308 (16) 921-925.

34 Leung A.Y., Suen C.K., Lie A.K., Liang R.H., Yuen K.Y., Kwong Y.L. (2001) Quantification of polyoma BK viruria in hemorrhagic cystitis complicating bone marrow transplantation. Blood. 98 (6) 1971-1978.

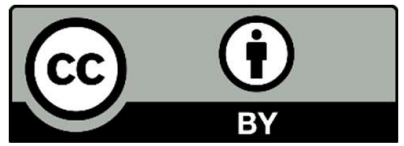

(C) 2020 by the authors; licensee Growing Science, Canada. This is an open access article distributed under the terms and conditions of the Creative Commons Attribution (CC-BY) license (http://creativecommons.org/licenses/by/4.0/). 